\title{
Commentary on "Role of Transcutaneous Electrical Nerve Stimulation in Treating Children With Overactive Bladder From Pooled Analysis of 8 Randomized Controlled Trials"
}

\author{
Isabel Casal Beloy, Miriam García González, Iván Somoza Argibay \\ Pediatric Urology Division, Pediatric Surgery Department, University Children’s Hospital of A Coruña, A Coruña, Spain
}

To the editor,

We read with great interest the recent contribution of Dr. Cui et al. [1] in their study, entitled "Role of Transcutaneous Electrical Nerve Stimulation in Treating Children With Overactive Bladder From Pooled Analysis of 8 Randomized Controlled Trials." They showed beneficial effects of transcutaneous electrical nerve stimulation (TENS) on non-neuropathic overactive bladder $(\mathrm{OAB})$ in children, and we would like to contribute some points regarding their paper.

The authors followed the PRISMA (Preferred Reporting Items for Systematic Reviews and Meta-Analyses) guidelines for carrying out the study. In the section describing the study's methodology, they affirmed that studies that met the eligibility criteria were included in the review; however, we were not able to find details on the specific inclusion and exclusion criteria in the text.

Secondly, the data extracted from the 8 articles included in this meta-analysis were presented in the Materials and Methods section. One of the scales used was the visual analogue scale (VAS). The authors mentioned that this scale was used to quantify pain secondary to the use of electrotherapy and they confirmed in the Results section that TENS did not cause pain or discomfort in pediatric patients with non-neuropathic OAB. However, the VAS, validated by Bower et al. [2] in 2001, is used to subjectively quantify symptoms due to urinary urgency, as well as temporary improvements in response to treatment, not to quantify pain or discomfort, as implied in this review.

Furthermore, none of the articles included in the review evaluated pain secondary to TENS in their results; therefore, it is impossible to draw the reported conclusion based on the results. The researchers in previous studies who used the VAS scale did so correctly - not to evaluate pain, but to assess subjective improvements in symptoms as perceived by patients and their families [3-6].

Finally, the latest guideline from International Children's Continence Society for the management of daytime incontinence emphasizes the importance of treating comorbidities associated with bladder dysfunction before the dysfunction itself [7]. The treatment of constipation is especially relevant for $\mathrm{OAB}$, since a high percentage of patients show improvement in bladder symptoms after the proper treatment of intestinal dysfunction [8].

However, most of the studies included in the meta-analysis by Cui et al. did not address the management of constipation in their methodology. In addition, in recent years, increasingly many studies have also demonstrated the benefits of TENS therapy in the management of constipation. Thus, the urinary symptoms of many patients included in this meta-analysis could have improved due to improvements in constipation, and not as a result of the use of TENS in isolation. Therefore, the overall efficacy of TENS for OAB reported in this review may have been overestimated.

We congratulate the authors for this study of TENS, as TENS has obvious advantages over previous proposed treatments (anticholinergic drugs, botulinum toxin, urotherapy). This tech-

Corresponding author: Isabel Casal Beloy (iD https://orcid.org/0000-0003-1762-8382 Department of Pediatric Surgery, University Children's Hospital of A Coruña, As Xubias, 84. CP: 15006. A Coruña. Spain

E-mail: isabelcasalbe@gmail.com

Submitted: May 11, 2020 / Accepted after revision: May 14, 2020

c) (1) $\$$ This is an Open Access article distributed under the terms of the Creative Commons Attribution Non-Commercial License (https://creativecommons.org/licenses/by-nc/4.0/) which permits unrestricted non-commercial use, distribution, and reproduction in any medium, provided the original work is properly cited. 


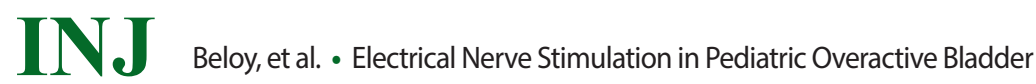

nique is a new and attractive alternative to conventional treatments for $\mathrm{OAB}$ in children. However, to establish the true benefits of this treatment, more randomized short- and long-term studies are needed. In addition, prior management of associated comorbidities, especially constipation, should be mandatory in all cases.

- Conflict of Interest: No potential conflict of interest relevant to this article was reported.

\section{REFERENCES}

1. Cui H, Yao Y, Xu Z, Gao Z, Wu J, Zhou Z, et al. Role of transcutaneous electrical nerve stimulation in treating children with overactive bladder from pooled analysis of 8 randomized controlled trials. Int Neurourol J 2020;24:84-94.

2. Bower W, Moore K, Adams R. A novel clinical evaluation of childhood incontinence and urinary urgency. J Urol 2001;166:2411-5.

3. Borch L, Hagstroem S, Kamperis K, Siggaard C, Rittig S. Transcutaneous electrical nerve stimulation combined with oxybutynin is superior to monotherapy in children with urge incontinence: a randomized, placebo controlled study. J Urol 2017;198:430-5.
4. de Paula LIDS, de Oliveira LF, Cruz BP, de Oliveira DM, Miranda LM, de Moraes Ribeiro M, et al. Parasacral transcutaneous electrical neural stimulation (PTENS) once a week for the treatment of overactive bladder in children: a randomized controlled trial. J Pediatr Urol 2017;13:263.e1-263.e6.

5. Lordelo P, Teles A, Veiga ML, Claudio L, Barroso JU. Transcutaneous electrical nerve stimulation in children with overactive bladder: a randomized clinical trial. J Urol 2010;184:683-9.

6. Hagstroem S, Mahler B, Madsen B, Djurhuus JC, Rittig S. Transcutaneous electrical nerve stimulation for refractory daytime urinary urge incontinence. J Urol 2009;182:2072-8.

7. Chang SJ, Van Laecke E, Bauer S, Von Gontarde A, Bagli D, Bower $\mathrm{W}$, et al. Treatment of daytime urinary incontinence: a standardization document from the International Children's Continent Society. Neurourol Urodyn 2017;36:43-50.

8. Casal-Beloy I, Somoza Argibay I, García-González M, García-Novoa AM. At-home transcutaneous electrical nerve stimulation: a therapeutic alternative in the management of pediatric overactive bladder syndrome. Influencia del sobrepeso y obesidad infantil en la apendicitis aguda en niños. Estudio de cohortes. Cir Pediatr 2020;33:30-5. 